PRE-RECORDED EXPERT EVIDENCE IN INTIMATE PARTNER VIOLENCE CASES

\author{
Jason M. Chin
}

Sydney Law School, University of Sydney, Australia; Institute for Globally Distributed Open Research and Education (IGDORE), Indonesia

This article is scheduled for publication in Current Issues in Criminal Justice 


\begin{abstract}
This article makes a case for pre-recorded, modularized expert evidence as a way to improve access to justice in some intimate partner violence (IPV) cases. Knowledge about the effects and dynamics of IPV regularly plays an important role in criminal trials. This knowledge is often beyond the ken of the factfinder, and thus can provide important context for the case facts. It may also assist in disabusing misconceptions surrounding IPV. Despite the potential value of this knowledge, several rules of evidence and the general nature of the Anglo-American trial process make it difficult to tender such evidence. For instance, trials prefer live testimony of expert witnesses over other means of conveying exogenous knowledge. These limitations place impecunious parties in regional areas at a disadvantage because they may struggle to find qualified experts. As a result, cross-examined pre-recorded modules about IPV (e.g., factors that prevent individuals from leaving abusive relationships, IPV as coercive control) may be helpful in some cases.
\end{abstract}




\section{KEYWORDS}

Intimate partner violence; expert evidence; pre-recorded evidence, admissibility; social framework evidence; battered woman syndrome 


\title{
PART I. INTRODUCTION
}

\author{
We consult concerning the obstacles, challenges, and insecurities that come up against the \\ simple act of delivering an element from one place to another. [...] Essentially, we exist \\ because of the tremendous difficulty inherent in simply transporting any entity from A to B \\ (Blotevogel 2017).
}

This article addresses the surprisingly difficult task of delivering knowledge about intimate partner violence (IPV) into courtrooms. IPV and the legal system regularly intersect (AIJA 2018). At the same time, there is a growing body of social scientific knowledge about the dynamics and effects of IPV (see e.g., US DOJ 1996; Stark 2007; Sheehy, Stubbs, and Tolmie 2014, 689-72). This knowledge can often provide relevant and helpful context for the facts of cases (Sheehy, Stubbs, and Tolmie 2014, 693). Despite these benefits, there remains the problem of packaging this knowledge as admissible expert evidence and delivering it into court. Qualified experts can be difficult to come by and are often only available to a select few. In this article, I propose an avenue that may be preferable in some circumstances: pre-recorded, modularized expert evidence (Mnookin 2015). This mechanism presents several advantages: it assuages reliability and fairness concerns that come with alternatives to expert witnesses, and it is more economical than requiring live experts in every case.

My proposal is limited to social framework evidence (sometimes also called empirical frameworks: Walker and Monahan 1987, Faigman, Monahan, and Slobogin 2014, 424-5, metaexpertise: Cole 2008, and educational expertise: Gross and Mnookin 2003, 163). Social frameworks are general, often group level research findings that are 'used to construct a frame of reference or background context for deciding factual issues crucial to the resolution of a specific 
case' (Walker and Monahan 1987, 559). They contrast with diagnostic or individuating evidence that say something about a specific case fact. For instance, framework evidence in the forensic science arena might be group-level research findings about how often fingerprint examiners tend to make errors when deciding whether two prints came from the same source. Individuating evidence, on the other hand, is a specific examiner's opinion and level of certainty about a fingerprint. In some cases, framework evidence might set the groundwork for individuation. In the forensics example, an examiner might refer to framework evidence in explaining the reliability of his or her case-specific conclusion (e.g., 'I tend to be this good at this type of task', see Edmond et al. 2006, 509). Or, similarly, a lawyer might rely on framework evidence to argue during submissions that the factfinder should or should not place much weight on the examiner's conclusion.

There appears to be significant demand for social framework evidence about IPV, but not enough readily available supply. This is demonstrated by courts looking beyond expert witnesses to more convenient (yet problematic - see Part V) sources, like evidence presented in previous cases. Furthermore, the fact that courts reuse this evidence demonstrates its applicability across multiple cases. Reusability suggests a diseconomy in that live experts are providing very similar evidence across many cases. My proposal addresses this diseconomy by allowing for prerecorded (and cross-examined) expert evidence to be deployed in cases in which it is relevant.

Parts II and III go on to provide brief primers on a type of case in which pre-recorded IPV testimony may be useful (Part II) and what exactly I mean by pre-recorded expert testimony (Part III). Then, in Part IV, I discuss how the rules of evidence can make it difficult for accused parties to tender expert evidence in IPV cases, and how pre-recorded expertise may satisfy those rules. Part V then explores some other alternatives to live expert witnesses, all of which carry 
with them serious downsides. Finally, Part VI, concludes with a summary of the advantages and disadvantages of pre-recorded expertise in IPV cases. This article will generally focus on Australian, US, and Canadian law, but the general principles should be applicable to most adversarial jurisdictions.

\section{PART II. SOCIAL FRAMEWORK EVIDENCE ABOUT IPV IN HOMICIDE CASES}

I will now discuss one type of case in which IPV knowledge often plays a role - cases in which a person who has experienced IPV attacks or kills their abuser and seeks to rely on a defence like self-defence ( $R v$ Runjanjic \& Kontinnen 1991), or refers to IPV knowledge in the context of sentencing ( $R v$ Tarrant 2018). I do not mean to suggest these are the only cases in which pre-recorded IPV modules may be of use (see Rathus 2018). Rather, they provide a convenient example because many of the cases in this context are precedent-setting and they have inspired a great deal of academic work.

Many commentators believe that in cases in which the accused experienced IPV, social framework evidence may help explain the dynamics of IPV to triers of fact who have not experienced or systematically studied it (Bradfield 2002, 184-85; US DOJ 1996, 4-17). Such evidence, for instance, may help tie together several temporally separated instances of violence, abuse, and control into a 'cohesive account of constant and persistent danger' (Bradfield 2002, 184). This may in turn help the factfinder understand the significance of the danger faced by the accused and to avoid seeing the events in question as disparate and unrelated. In non-traditional self-defence cases (i.e., when the accused was not in immediate danger) especially, social framework evidence can drive home the fact that while there might not have been a stereotypical threat present (e.g., a gun to the head), the circumstances had risen to a level that could explain 
the accused's response (Sheehy, Stubbs, and Tolmie 2016). Similarly, knowledge about the social structures and economic pressures that play a demonstrable role in IPV may provide the factfinder helpful context for understanding the facts of the case (US DOJ 1996, 14-15).

Social framework evidence may also be tendered to describe the general responses of those experiencing IPV (US DOJ 1996, 10-15). For example, evidence from the psychology of trauma explains that it is common for individuals to experience memory loss and emotional attachments to their abuser as a result of battering (US DOJ 1996, 12, 15). Trauma research also provide insights into how those experiencing IPV (and sometimes re-experiencing it through flashbacks) regularly develop appraisals of the situation that diverge from what outsiders comprehend (US DOJ 1996, 7-9; $R$ v Tarrant 2018, [96]). Similarly, sociological and psychological evidence can explain that it is common for those experiencing IPV to stay in the relationship and be uncooperative in attempts to prosecute their partners (US DOJ 1996, 14-17).

The above evidence, besides providing important context, can have other salutary effects. For instance, it may help mitigate unfounded threats to the accused's credibility (Sheehy, Stubbs, and Tolmie 2016, 705-7; Bradfield 2002, 188-89). In Queensland's $R v$ Falls case, for instance, expert witnesses provided a wide range of social framework evidence: '[T]he experts gave evidence that it was typical for abused women to be isolated, to hide their abuse, to lie about the cause of their injuries, to have memory loss because of trauma, and to fail to seek medical help' (Sheehy, Stubbs, and Tolmie 2016, 700). This evidence helped 'normalise' some of the accused's responses and behaviours, thus preserving her credibility (Sheehy, Stubbs, and Tolmie 2016, 706; in Canada, see e.g., $R$ v Reid 2003, $R$ v S(JP) 2001). In other cases, psychological evidence explaining why those who have experienced trauma do not always show a lot of affect 
or emotion might help the factfinder understand why an accused is not especially emotional when testifying or during previous interviews (US DOJ 1996, 12).

Evidence like that in Falls may also disabuse misconceptions held by some of the public (see also McKimmie and Masser 2020). Indeed, while the public's perception of IPV is catching up with the research, it is likely that many people still labour under serious misconceptions (Bradfield, 2002, 181-83; Webster et al. 2018). For instance, 32\% of the over 17,000 respondents to the 2017 National Community Attitudes towards Violence against Women Survey (NCAS) agreed with the statement that 'A female victim who does not leave an abusive partner is partly responsible for the abuse continuing' (Webster et al. 2018, 82). Several other responses to the NCAS include (Webster et al. 2018, 82):

- $16 \%$ agreed that 'I don't believe it's as hard as people say it is for women to leave an abusive relationship';

- $12 \%$ agreed that 'If a woman keeps going back to her abusive partner then the violence can't be very serious';

- $11 \%$ agreed that 'Women who stay in abusive relationships should be entitled to less help from counselling and support services than women who end the relationship'; and

- $11 \%$ agreed that 'Women who wait weeks or months to report sexual assault are probably lying'.

\section{PART III. A PRIMER ON PRE-RECORDED MODULES}

The previous section indicates that there are several topics of IPV knowledge that may assist adjudicating cases. In other words, knowledge about IPV may be broken down into legally relevant modules. One module might, for instance, focus on leaving relationships that involve 
IPV. This could include the reasons people do or do not leave such relationships and the research underlying these conclusions, like statistical summaries and other aggregations of case studies.

So, what is the best way of getting these modules into court and admitting them into evidence? Recently, in the context of social scientific evidence about eyewitness memory and false confessions, Jennifer Mnookin (2015, 1818-20) suggested these modules could be prerecorded and played for judges and juries.

Mnookin's idea, which I think is well-suited to the IPV context (for slightly different reasons that I get into below), is rather straightforward. Modules would be arranged like typical testimony, with direct and cross examination. Ideally, the experts providing the testimony will be noted leaders in the area covered in the module. This will enable them to speak knowledgably about the topic and the research underlying it - both the field's strengths and limitations. The modules should be prepared by a neutral organization and the process for deciding which modules to prepare should be conducted as openly and inclusively as possible. This might include meetings between social scientific experts, legal scholars, lawyers and judges. The modules ought to be fully peer-reviewed by other experts in the area, with any reasonable disagreement discussed in the module itself. The modules should be updated periodically to reflect new research in the area.

The question of where to find, or how to construct, a neutral organization is challenging. Mnookin did not provide much guidance when it came to eyewitness memory modules, except to say it should be a 'well-regarded, structurally neutral organization, not affiliated with either the defense bar or the prosecutors.' (Mnookin 2015, 1819). The IPV context presents the distinctive difficulty in that organizations in this area may be, or may be seen to be, aimed at advocacy work, rather than the per se creation and dissemination of knowledge. 
Any organization that takes on pre-recorded modules can both assuage some concerns with its neutrality and help ensure justice is done by taking advantage of recent research and organizational efforts to synthetize knowledge in a systematic and transparent way. For instance, in health-related fields, the Cochrane Collaboration strives to produce systematic reviews of evidence that clearly lay out the overall strength of support for a finding, while highlighting potential biases in literature (e.g., certain types of findings being unreported, see Higgins et al 2019; Haddaway et al 2020). Similarly, researchers in a variety of fields are increasingly relying on a protocol called Preferred Reporting Items for Systematic Reviews and Meta-Analyses (PRISMA) when conducting reviews of existing evidence to transparently document evidence included and not included in their review (Nakagawa et al 2020; Moher et al 2009). This rigour and transparency promoted by Cochrane and PRISMA may help ensure both the accountability of organizations producing pre-recorded modules (Chin et al 2019) and the long term credibility of their work (Vazire \& Holcombe 2020).

\section{PART IV. THE (CURRENT) LEGAL AND PRACTICAL CHALLENGES TO FINDING AND ADMITTING IPV KNOWLEDGE}

Before delving into the advantages and disadvantages of pre-recorded IPV modules, it is instructive to examine the applicable rules of evidence that they will be asked to conform to. This generally serves two ends. First, we will see that the expert evidence rules are, for the most part, rationally related to the objective of restricting expert evidence to that which is helpful and relevant. However, when expertise is rare, expensive, and unevenly distributed in the world when there is a difficulty in getting it from $\mathrm{A}$ to $\mathrm{B}-$ the expert rules may contribute to injustice. As a result, pre-recorded modules may prove a second-best option to retaining the appropriate mix of live expert witnesses. Second, we will see that expert modules, despite not conforming to 
our traditional idea of a witness, can be designed in a way that provides relevant and reliable information.

\section{A Battered Woman Syndrome (BWS) primer}

Expert evidence about IPV initially broke through into Australian $(R v$ Runjanjic \& Kontinnen 1991), Canadian ( $R$ v Lavallee 1990), and US (New Jersey v Kelly 1984) courts in the form of Battered Woman Syndrome (BWS). BWS is both a pattern of violence against women and a set of reactions to that violence (McMahon 1999, 26). The pattern is often described, in academic writing and in court, as a cycle of tension building, acute battering, and contrition, which the woman begins to anticipate in a way that outsiders to the relationship may not (McMahon 1999, 27-8; $R v$ Runjanjic \& Kontinnen 1991, 117-8). The psychological effects include elements of post-traumatic stress disorder (e.g., fear, panic, re-living the trauma) and learned helplessness (i.e., a lack of self-efficacy to change one's circumstances and thus not seeing leaving the relationship as a viable option; McMahon 1999, 28-9).

Prominent jurists and commentators have criticised BWS and its use in criminal trials on multiple grounds $(R \vee M(M A)$ 1998, [35]-[45]; $R \vee$ Osland 1998, [154]-[179]; US DOJ 1996, $17-$ $20)$. For instance, BWS provides a narrow account of the victimization of women $(R \vee M(M A)$ 1998, [40]; $R$ v Osland 1998, [160]-[161]). As a result, BWS as a framing mechanism for expert evidence may deny justice to individuals who cannot place themselves within its narrative. Moreover, the initial research on BWS focused on the experience of middle-class Caucasian women from industrialized countries ( $R v$ Osland 1998, [161], citing Stubbs and Tolmie 1995). This is, in fact, a characteristic of much of the published psychological literature, which has traditionally been focused on what are known as WEIRD samples (Western, Educated, 
Industrialized, Rich and Democratic; Henrich, Heine, and Norenzayan 2010). WEIRDness complicates BWS and its application to legal matters. It creates the need for an expert who can explain the ways in which the framework may or may not be generalizable and the need for an advocate who can explain to the court that, while the background research does not precisely fit the facts of the case, it may still be relevant.

Now, we will briefly walk through the rules of evidence that BWS and other IPV knowledge often engages with. In particular, IPV knowledge frequently enters the court as expert evidence. The expert evidence rules include relevance, going beyond common knowledge, reliability, coming from a properly qualified expert, and having its benefits outweigh its costs to the trial.

\section{$\underline{\text { Relevance }}$}

Like all evidence, social framework evidence about IPV must be relevant to be admissible ( $R v$ Runjanjic \& Kontinnen 1991; $R$ v Mohan 1994; NSW, Evidence Act 1995, s 55; US Federal Rules of Evidence, R 702(a)). Evidence is relevant if can rationally affect the assessment of a fact in issue (see, e.g., NSW, Evidence Act 1995, s 55). The primary source of relevance of social framework evidence is providing general context that allows the trier of fact to then infer something about the case specific facts (Walker and Monahan 1987, 575). This means that the relevance determination is highly dependent on the applicable law (e.g., any defence being raised) and the facts of the case.

The repeat-play nature of the modules I am proposing - despite the fact that they are not designed to speak to the facts of a specific case - does not mean they would fail for lack of relevance. In fact, there is strong precedent that this type of evidence is relevant. This feature of 
much of the jurisprudence was explicit in $R v$ Runjanjic and Kontinnen (1991, 120, emphasis added), the first Australian case to admit BWS evidence:

\begin{abstract}
The proffered evidence is concerned not so much with the particular responses of these appellants as with what would be expected of women generally, that is to say, women of reasonable firmness, who should find themselves in a domestic situation such as that in which the appellants were. It is designed to assist the court in assessing whether women of reasonable firmness would succumb to the pressure to participate in the offences. It also serves to explain why even a woman of reasonable firmness would not escape the situation rather than participate in criminal activity. As such it is relevant.
\end{abstract}

A second component of relevance, which is only applicable to expert evidence, is what is sometimes called 'empirical fit' (Faigman, Monahan, and Slobogin 2014, 441-3). Expert evidence empirically fits the case if the research underlying the expertise corresponds to the facts of the case. Empirical fit is similar to the scientific notion of 'external validity', the degree to which studies can be generalized outside of their specific context (Faigman, Monahan, and Slobogin 2014, 442-3).

An issue of empirical fit arose in WA v Carlino (2014), in which an expert would have discussed BWS in the context of a same-sex relationship. Justice Hall excluded the evidence for lack of empirical fit (without using that term). In particular, he noted it was possible that BWS could apply beyond its traditional subject matter, but that he was not provided sufficient evidence that it did (WA v Carlino 2014, [24]):

The possibility that the syndrome may extend to relationships other than that of husband and wife does not obviate a need for proof that this possibility has been widely accepted by experts in the field. In cross-examination Mr Cummins [the expert witness] said that he was unable to identify any research or published papers confirming that battered wife syndrome could extend 
to situations like that of the accused. He said, however, that he had encountered it in his own experience and could give case studies. He said that over time the syndrome had been recognised as arising in factual situations other than women in long term marriage like relationships.

Justice Hall found the expert's experience insufficient to demonstrate relevance to the facts of Carlino, instead requiring 'there be evidence to prove that the application of the syndrome to a situation like this is accepted by the majority of experts in the field of psychology' (WA $v$ Carlino 2014, [26]). In short, Hall $\mathbf{J}$ seemed to be asking for reliable evidence establishing empirical fit.

Carlino demonstrates a challenge in adducing framework evidence about IPV that prerecorded modules may help address. In particular, framework expertise requires a knowledge base that often goes beyond the first-hand experiences of the witness. The expert in Carlino was prepared to refer to his own case work, but he did not have the more general knowledge that the trial judge was looking for - knowledge that would bridge the gap between BWS as the trial judge understood it and the circumstances of the case. Pre-recorded modules would have the benefit of a more extensive research process behind them and experts that may speak more broadly about the existing research than practitioners may be placed to speak to.

That said, Carlino also demonstrates a resistance that pre-recorded modules may face, in particular that the research underlying them is too far removed from the facts of the case to be relevant. Before discussing how this limitation may be dealt with, it is worth noting that empirical fit is an issue that impacts most, if not all, framework evidence. Yes, BWS is built on WEIRD foundations, but, so is most psychological research (Henrich, Heine, and Norenzayan 2010, 61). This does not mean that the research only applies to other WEIRD people. Rather, it 
should be applied cautiously and in a principled way. This is a feature of the scientific process and not something that is typically seen as an absolute bar to admissibility. Indeed, the trial judge in Carlino later admitted BWS evidence in a different case involving a Sri-Lankan couple without apparent hesitation based on BWS's WEIRDness (Liyanage v WA 2017, [50]).

Pre-recorded modules may anticipate the Carlino objection in two ways. First, perhaps a module should be created that addresses IPV in same sex-relationships (and other areas where there is sufficient research to develop a module). There may be enough of these types of cases to make this work worthwhile (see $R v$ McEwan, discussed in Stubbs and Tolmie 1999, 744-45). Second, all modules should be very clear about the research underlying them and the degree to which the expert believes they would or would not generalize beyond those samples. It would then be up to the trier of fact to determine how well the framework evidence fits the facts of the case when determining how much weight to assign it. This, despite the outcome in Carlino, is the traditional role of trier of fact and something we regularly trust them to do (Faigman, Slobogin, and Monahan 2016; Mnookin 2015, 1819-20).

There remains, however, the more systemic and difficult problem of WEIRD research (and research limited in other ways) denying justice to individuals who cannot fit themselves into the demographic or type focused on by the research (Sheehy, Stubbs, and Tolmie 1992; Randall 2010). While I acknowledge this serious limitation, the modularization of expert evidence may still provide some assistance by allowing individuals to find an aspect of the evidence that can be applied to their circumstances (e.g., economic difficulties that make it difficult to leave an abusive relationship). I also hope that any organization taking on the development of prerecorded modules would engage in a planning process that identifies the need for modules in 
communities that criminal justice systems have systematically failed and to highlight deficiencies in the way such cases are currently handled.

\section{Common knowledge}

Even if expert evidence is relevant, it may still be excluded if it overlaps too much with knowledge the trier of fact likely possesses. This requirement is expressed in the common law (Clark v Ryan 1960, 491; $R$ v D(D) 2004; Goss 2020) rule against common knowledge (i.e., evidence that is 'within the ken') that has been removed through statutory reform in Australia and the US (Chin and Crozier 2018, 626). Still, some inquiry into whether the evidence is common knowledge informs whether the evidence meets the broader requirement that expert evidence be specialized knowledge and that its benefits to the trial process outweigh its costs (Odgers 2018, 594-5; ALRC 1985, [743], see below under 'The trial judge's residual discretion to exclude').

Social scientific evidence is particularly vulnerable to exclusion as common knowledge under the reasoning that judges and juries understand human nature and so they do not need an expert to explain it to them (Chin and Crozier 2018). The need to portray IPV knowledge as more than common knowledge initially contributed to it being framed as BWS, a condition experienced by certain people (Walker, Thyfault, and Brown, 1982; Faigman and Wright, 1997). As I have suggested elsewhere, the implicit reason for this move was to fit with the human bias known as dispositionism, whereby people tend to prefer disposition-driven explanations for behaviour as opposed to situational explanations (Chin and Crozier 2018, 642).

BWS helped IPV expertise over the common knowledge hurdle in Runjanjic but seemingly only by the narrowest of margins. Chief Justice King said he 'considered anxiously 
whether the situation of the habitually battered woman is so special and so outside ordinary experience' ( $R$ v Runjanjic \& Kontinnen 1991, 121) that it should be admitted. This decision did clearly acknowledge that situational evidence could pass the common knowledge hurdle and that BWS itself was not a clinical diagnosis. Still, the court's reluctance was clear. In any case, and despite some pushback ( $R v$ Tarrant 2018, [43]-[44]), IPV knowledge is still regularly couched in terms of BWS in Australian and Canadian courts (Liyanage v WA 2017; $R$ v Silva 2015; $R v$ Young 2008), and sometimes excluded if it does not fall neatly into the BWS package ( $R$ v Jones 2015; Rv Li 2016).

Pre-recorded modules, by their nature, cannot speak to whether the accused suffers from some syndrome. And they cannot change the Western preference for dispositional evidence (East Asian cultures tend to be more accepting of situational evidence, Choi, Nisbett, and Norenzayan, 1999). That said, they may help mollify the undue scrutiny social framework evidence receives in other ways. By providing expert evidence from a neutral body and from leading experts, courts (those in common law evidence jurisdictions, especially) may be less concerned with the evidence's apparent overlap with common knowledge. In other words, pre-recorded modules may reduce other concerns about the evidence that may be in the back of the judge's mind, such as the possibility that the expert is partisan or is usurping the factfinder's role. Judges may also worry less about the extending the trial with lengthy voir dires and examinations because those timeframes are known entities with pre-recorded modules.

\section{$\underline{\text { Reliability }}$}

Next in our tour through the rules of expert evidence is the requirement that the evidence be sufficiently reliable. This rule is unevenly applied, and its substance varies considerably by 
jurisdiction. In Canada and the US, expert evidence must meet a threshold level of reliability to be admitted (White Burgess Langille Inman v Abbott and Haliburton Co 2015, [23]; Daubert v Merrell Dow Pharmaceuticals Inc 1993). In Australia, courts have refrained from reading reliability into the Uniform Evidence Law (Edmond 2015). In Australian common law evidence jurisdictions, reliability remains a component of the admissibility calculus, but it is rarely applied outside of the social science context. Compare, for instance, the reliability scrutiny in WA $v$ Liyanage (2016) to a lack of such scrutiny of forensic science in $R v$ Sica (2013).

Pre-recorded modules should not face any reliability difficulties. Consider, by analogy, Mnookin's proposal for modules about eyewitness memory and false confessions. Psychologists in those fields cannot reliably say if a particular identification or confession is accurate (Mnookin 2015, 1846-47) and so modules fit well with this scientific limit because they are not case specific. Similarly, an IPV researcher could not provide the diagnostic evidence of saying what a particular accused person's reasons were for staying in a violent relationship - and such information could not be present in pre-recorded modules due to their general nature. Moreover, mainstream use of pre-recorded modules may dissuade lawyers from encouraging experts to step outside the boundaries of their fields by providing unreliable diagnostic evidence.

\section{Qualifications}

The expert must be also qualified to provide the proffered evidence. Here, the rule is generally the same at common law and under statutory reform: the expert must have acquired the expertise by training, study, or experience (NSW, Evidence Act 1995, s 79; US Federal Rules of Evidence, R 702; The Queen v Bonython 1984, 47). With respect to this rule, pre-recorded modules may be useful by connecting the framework knowledge of qualified experts to parties 
who would not normally be able to obtain it. This is because, as I will now discuss, framework knowledge often requires considerable study, and so experts may be difficult to find.

Framework evidence naturally demands that the expert's qualifications flow more from the 'study' component of the above factors and less from the 'experience' component (Faigman, Monahan, and Slobogin, 2014, 444-47). In other words, general knowledge often goes beyond a single researcher or practitioner's work, drawing on many observations, studies, meta-analyses, and literature reviews (Faigman, Monahan, and Slobogin, 2014, 445):

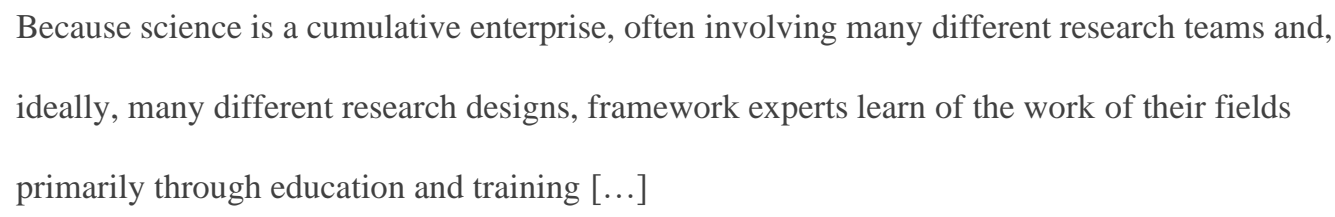

In IPV cases, in will be difficult for a single practitioner to provide sufficient framework evidence because the study of IPV is an expansive and interdisciplinary topic. Liyanage provides an example of this whereby both the trial judge and appellate court - for varying reasons - noted that a social worker (Ms Cooke) lacked the qualifications to support some of her evidence (WA $v$ Liyanage 2016, [85]; Liyanage v WA 2017, [163]. In particular, Cooke would have provided evidence about the psychological effects of IPV. The court of appeal noted, however, that her expertise was not in fields that study and typically apply those concepts: 'A large amount of Ms Cooke's evidence, which in effect concerned the psychological impact of prolonged exposure to domestic violence, did not concern a subject matter on which she was qualified to give opinion evidence in court.' (Liyanage v WA 2017, [163]). Note, however, that in Liyanage, other experts did provide such evidence (Liyanage $v$ WA 2017, [49]-[55].

The trial judge, Hall J, went a bit further than the court of appeal, expressly stating that Cooke had neither the requisite qualifications to provide the framework, nor the qualifications to 
apply the framework to the facts (WA v Liyanage 2016, [85]). Here, Hall J's reasoning is somewhat strained. While, indeed, Cooke may have not studied the psychology of IPV enough to provide the framework, she may have been able to apply a framework established by another expert. In other words, Cooke likely had the requisite expertise through her extensive work with those experiencing IPV to recognize the processes explained by a framework expert and to link them to the instant case (whether that task is better left to the lawyers and ultimately the factfinder is another matter). After all, this is what practitioners do. In cases like these, prerecorded modules may assist by providing robust framework evidence that can be applied by experts like Cooke (see Ewert v Canada 2018, where the need for such evidence arose) or adverted to by the lawyer during their submissions (State v Batangan 1990; State v Guilbert 2012).

The trial judge's residual discretion to exclude

To conclude our review of the rules of expert evidence, consider the trial judge's residual discretion to exclude evidence when its costs to the trial process exceed its benefits (see NSW, Evidence Act 1995, ss 135-137; US Federal Rules of Evidence, R 403; $R$ v Christie 1914; White Burgess 2016). It is worth noting that made-in-advance expert testimony assuages some of the costs of expert evidence, perhaps making it less likely such evidence will be excluded. In particular, pre-recorded evidence is less likely to be biased by the adversarial process than evidence that comes about as a result of a particular dispute. By its nature, it cannot have been brought about as the result of a particular adversarial dispute. And, as noted above, it may take up less court time because its merit has already been thoroughly tested. 
Finding and retaining an expert with admissible IPV knowledge

The above discussion highlighted some of the pressures that evidence law places on parties seeking to tender expert evidence. For the most part, these are sensible hurdles: expert evidence ought to be relevant and reliable, and experts ought to be properly qualified.

However, when there are severe practical and logistical constraints in finding and retaining expert witnesses, the rules of evidence can contribute to injustice. Expert evidence on IPV and its effects relies on accumulated knowledge from a variety of disciplines. Finding and retaining a qualified expert - likely multiple experts - who have an interest in appearing in front of a court is a lot to ask for people who already find themselves in oppressive situations. These pressures are heightened in remote areas and smaller jurisdictions, where it 'may be particularly difficult to find local psychologists or psychiatrists who have sufficient expertise to testify appropriately' (Sheehy, Stubbs, and Tolmie 2016, 697).

\section{PART V. ALTERNATIVES TO EXPERT EVIDENCE AND THEIR LIMITS}

The constraints in Part IV converge with a broader discussion into how to best get 'outside' or 'exogenous' knowledge into courtrooms (Burns, Dioso-Villa, and Rathus 2016, 28384). Some ways in which such knowledge gets into courtrooms without experts are judicial notice, judicial instructions based on social science, and the implicit assumptions and background knowledge of the factfinder (Rathus, 2018; Burns, Dioso-Villa, and Rathus 2016; Mnookin 2015, 1837-42). And, in the IPV context in particular, judges sometimes refer to evidence admitted in other trials and other judges' findings about that evidence (Stubbs and Tolmie 1999, 719-20; $R$ v Lalonde 1995; $R$ v O'Neil-Shaw 2009, [31]; Kalenik v Apostolidis 2009, [592]; Heilig v Cabiness 2011, [30]; $R v$ Hamid 2006, [76]-[78]). This occurred in the 
Ontario Court of Justice's decision $R v$ Lalonde (1995, [25]). The trial judge said it would be inappropriate, especially given it was a legal aid case, to hew closely to the rules of evidence. In doing the judge quoted a similar decision of the Yukon Territories Court (R v Lalonde 1995, [27]):

It would be both absurd and wasteful to require expert witnesses to attend court for the purpose of describing the generic battered wife syndrome. Such experts may not be available in remote and isolated communities.

All of the above work-arounds to expert evidence have attracted criticism (For criticism of social science admitted through judicial notice and the judge's own understanding and research, see Rathus 2018, 98-104; for criticism of reliance on factual findings in other cases, see Larsen 2013). For the purposes of this article about IPV knowledge, my most serious concern is that social scientific evidence is just that - it's evidence. Extant findings are not beyond dispute. Moreover, theories change over time in light of new findings, with theories regularly contested, narrowed, or abandoned altogether. Indeed, the judge of the Yukon Territories Court might be surprised to know that 'generic battered wife syndrome' has never had a strong research tradition behind it ( $R v$ Lalonde 1995, [27]; Faigman and Wright 1997). Admission of social scientific evidence in a previous decision, even that of a higher court, is not a strong indicator of reliability.

Another idea, one closer akin to what I am proposing, is the development of judicial instructions about IPV by an institutional body with the appropriate expertise. These could then be read to the jury and into the record by the judge in appropriate cases (see the discussion of the value of experts vs judicial instructions in $R v D(D) 2000)$. While this approach is more promising, its fundamental shortcoming is what Mnookin calls a 'category error', or 'taking a set of issues that are properly understood as evidence and attempting to turn them into instructions 
instead' (Mnookin 2015, 1842). Presenting social scientific evidence this way sits awkwardly with the rest of the judge's directions and instructions, and may give this evidence an unearned patina of authority.

\section{PART VI. THE CASE FOR PRE-RECORDED IPV KNOWLEDGE}

As we saw above, meeting the legal expectations of expert evidence can be challenging in the context of IPV knowledge. This is interdisciplinary, sometimes WEIRD work that is created and studied by people with considerable demands on their time, and who may not be in the right geographic area at the right time. The alternatives to expertise also all bring with them serious limitations and concerns. So, how does pre-recorded expertise stack up against the alternatives? I will now do that calculus, generally finding that pre-recorded IPV expertise is an option worth pursuing.

First, consider pre-recorded expertise as compared to expert-alternatives that give the judge a more active role in identifying relevant knowledge. The advantage of expert modules here are that they are more in keeping with both the traditional roles and competencies of the judge, witness, and factfinder. Judges simply are not trained to wade into the social science literature and identify the most reliable and relevant research, even when such evidence has been admitted in previous decisions. Moreover, in the family law context at least (without a jury), there is an established concern that the judge as factfinder may bring into the courtroom a mistaken view of human nature (Rathus 2018, 102-3). Pre-recorded modules may help disabuse those misconceptions and bring (relatively) up-to-date social science into the factual record.

What about pre-recorded modules as compared to live witnesses? Here, made-in-advance modules are, in most cases, a second-best option. Experts do more than provide testimony. They 
may, for instance, meet with the lawyers and advise about how their expertise is relevant to the facts of the case, eventually providing a report. None of that will be possible with pre-recorded experts. Similarly, the bespoke option can be more narrowly tailored to the precise circumstances of the case and can contain more up-to-date knowledge. There are also many practical concerns with creating the modules to begin with. The process requires an appropriate institutional body, funding, and that all stakeholders buy in to the process - a consensus that may be hard to find.

Still, there are benefits - even as compared to live witnesses - that holdouts may be encouraged by. For instance, the job of cross-examining an IPV expert is surely a time consuming one, requiring a great deal of research and perhaps consultation with other experts. Those tasked with this cross-examination - Crown counsel in the cases I have focused on - may be happy to see their job outsourced to someone with a great deal of experience in such cases.

There may also be benefits to the party calling the expert. For instance, there is a concern that traditional expert witnesses may seem liked hired guns in the trial context, saying whatever is best for the client (Chin, San Roque, McFadden 2020). Pre-recorded experts will not carry as much of that stigma because they are insulated from the case itself.

More generally, pre-recorded expertise addresses the too-familiar complaint about expert witnesses not providing sufficient research to back up their assertions; their testimony sometimes relies heavily on their bare say-so (Rathus 2018, 108; Edmond, Martire, and San Roque 2017). Pre-recorded modules can do better than this because their creators will have more time to prepare them in advance, which allows for clearer referencing. And finally, the fact that modules are pre-recorded reduces the risk of encroaching on the role of the trier of fact in deciding how the evidence applies to the facts. In other words, the pre-recorded expert cannot be pushed by the 
adversarial pressures of the trial to say something fact-specific, like about the credibility of a particular witness.

Finally, from a doctrinal standpoint, pre-recorded modules raise hearsay concerns that live experts are exempt from (see Dasreef Pty Ltd v Hawchar 2011). These concerns are especially forceful in the U.S., where the constitution guarantees the accused's right to confront testimonial evidence adduced against them (Mnookin 2008). In some ways, this restriction is illconceived. As Ed Cheng and Alex Nunn recently noted, the modern witness-centric trial developed in a time when evidence was more ad hoc in nature: ‘...the witness-focused trial emerged in an era when individuals made observations, took actions, and made decisions on an ad hoc subjective basis" (Cheng and Nunn 2019, 1078). Similarly, within the sciences, researchers could not share work as readily and stand on each other's shoulders (Wootton 2015, 327). Researchers, as a result, were much more isolated and self-sufficient. Accordingly, it made more sense to require a live expert witness that could be tested as to his or her reliability and credibility.

Nowadays, the hearsay restriction is somewhat inapposite, especially in the context of framework evidence. This is because framework evidence depends neither on a specific researcher, nor on the facts of a specific case. In other words, its reliability does not hinge on the skill of the particular witness reporting the framework knowledge, but the scientific processes that generated this accumulated knowledge. These processes, in social science, include careful observation, thorough reporting of findings, and peer review. These indicia of reliability will not vary much on a case-by-case basis. Creators of expert modules might assuage hearsay concerns by making the process for developing them as transparent as possible, thereby making them retrospectively examinable. This may inspire courts to make special allowances for pre-recorded 
modules, perhaps creating procedures and practices for their admission (this may mirror recent law reform cutting into the hearsay rule by allowing pre-recorded factual testimony in some cases, Roberts 2019).

Overall, pre-recorded IPV modules will almost certainly meet some resistance. And further study may find that it is not economical to create the full range of them, but rather just a certain set of commonly-engaged topics that are particularly prone to misunderstanding. Still, this research and consideration is worthwhile. The existing ways of bringing exogenous knowledge into courtrooms have all proved seriously deficient. Pre-recorded expert modules represent a first step in tackling the surprisingly difficult problem of transporting knowledge from A to B. 


\section{ACKNOWLEDGEMENTS}

I heartily thank two anonymous reviewers and Heather Douglas for their perceptive and wellconsidered feedback. I also thank the participants of the December 2019 workshop, Crime in the Intimate Sphere: Issues in Evidence, held at the Supreme Court of Queensland in Brisbane. 


\section{REFERENCES}

AIJA (Australasian Institute of Judicial Administration). 2018. National Domestic and Family Violence Bench Book.

ALRC (Australian Law Reform Commission). 1985 Evidence, Report No 26.

Blotvogel, Jill E. 2017. “The Structural Dynamics of Flow” Patriot, Directed by Tucker Gates. Zaftig Films.

Bradfield, Rebecca. 2002. "Understanding the Battered Woman Who Kills her Violent Partner

— The Admissibility of Expert Evidence of Domestic Violence in Australia" Psychiatry, Psychology and Law 9(2): 177-99.

Burns, Kylie, Rachel Dioso-Villa, and Zoe Rathus. 2016. "Judicial decision-making and 'outside' extra-legal knowledge: breaking down silos” Griffith Law Review 25(3): 283-90.

Cheng, Edward K. and G. Alexander Nunn. 2019. "Beyond the Witness: Bringing A Process Perspective to Modern Evidence Law" Texas Law Review 97(6): 1077-1124.

Chin, Jason M., Mehera San Roque, and Rory McFadden. 2020. "The New Psychology of Expert Witness Procedure" Sydney Law Review 42(1): 69-96.

Chin, Jason M., Gianni Ribeiro, and Alicia Rairden. 2019. “Open Forensic Science” Journal of Law and the Biosciences 6(1): 255-88.

Chin, Jason M. and William E. Crozier. 2018. "Rethinking the Ken Through the Lens of Psychological Science" Osgoode Hall Law Journal 55: 625-64. 
Choi, Incheol, Richard E. Nisbett, and Ara Norenzayan. 1999 "Causal attribution across cultures: Variation and universality" Psychological Bulletin 125(1) 47-63.

Cole, Simon A. 2008. "Out of the Daubert Fire and into the Fryeing Pan? Self-Validation, MetaExpertise and the Admissibility of Latent Print Evidence in Frye Jurisdictions" Minnesota Journal of Law, Science \& Technology 9(2): 453-542.

Edmond, Gary. 2015. “A Closer Look at Honeysett: Enhancing Our Forensic Science and Medicine Jurisprudence" Flinders Law Journal 17: 287-329.

Edmond, Gary, Bryan Found, Kristy Martire, Kaye Ballentyne, David Hamer, Rachel Searston, Matthew Thompson, Emma Cunliffe, Richard Kemp, Mehera San Roque et al. 2006. “Model Forensic Science” Australian Journal of Forensic Sciences 48(5): 496-537.

Edmond, Gary, Kristy Martire, and Mehera San Roque. 2017. "Expert Reports and the Forensic Sciences” UNSW Law Journal 40(2): 590-637.

Faigman, David L., and Amy J. Wright. 1997. "The Battered Woman Syndrome in the Age of Science" Arizona Law Review 39(1): 67-116.

Faigman, David L., John Monahan, and Christopher Slobogin. 2014. “Group to Individual (G2i) Inference in Scientific Expert Testimony" University of Chicago Law Review 81(2): 417-80.

Faigman, David L., Christopher Slobogin, and John Monahan. 2016 "Gatekeeping Science: Using the structure of scientific research to distinguish between admissibility and weight in expert testimony" Northwestern University Law Review 110(4): 859-904.

Goss, Caitlin. 2020, this issue. "Common knowledge in the common law: challenges in domestic violence cases" Current Issues in Criminal Justice. 
Gross, Samuel R and Jennifer L. Mnookin. 2003. "Expert Information and Expert Evidence: A Preliminary Taxonomy” Seton Hall Law Review 34: 141-89.

Haddaway, Neal R., Elie A. Akl, Matthew J. Page, Vivian A. Welch, Ciara Keenan, and Tamara Lotfi. 2020. "Open synthesis and the coronavirus pandemic in 2020” Journal of Clinical Epidemiology.

Henrich, J., Steven J. Heine, and Ara Norenzayan. 2010. “The weirdest people in the world?” Behavioral and Brain Sciences 33: 61-135.

Higgins, Julian P. T., James Thomas, Jacqueline Chandler, Miranda Cumpston, Tianjing Li, Matthew J. Page, and Vivian A. Welch, eds. 2019. Cochrane handbook for systematic reviews of interventions. John Wiley \& Sons.

Larsen, Allison Orr. 2013. "Factual Precedents" University of Pennsylvania Law Review 162: 59-115.

McKimmie, Blake and Barbara Masser. 2020, this issue. "Sexual assault in the context of intimate partner relationships" Current Issues in Criminal Justice.

McMahon, Marilyn. 1999. "Battered women and bad science: The limited validity and utility of battered woman syndrome" Psychiatry, Psychology and Law 6(1): 23-49.

Mnookin, Jennifer L. "Expert Evidence and the Confrontation Clause After Crawford v. Washington" Journal of Law and Policy 15(2): 791-862.

Mnookin, Jennifer L. 2015. “Constructing Evidence and Educating Juries: The Case for Modular, Made-In-Advance Expert Evidence About Eyewitness Identifications and False Confessions" Texas Law Review 93: 1811-48. 
Moher, David, Alessandro Liberati, Jennifer Tetzlaff, Douglas G. Altman, and Prisma Group. 2009. "Preferred reporting items for systematic reviews and meta-analyses: the PRISMA statement" PLoS med 6(7): e1000097.

Nakagawa, Shinichi., Adam G. Dunn, Malgorzata Lagisz, Alexandra Bannach-Brown, Eliza M. Grames, Alfredo Sánchez-Tójar, Rose E O’Dea, Daniel WA Noble, Martin J Westgate, Pieter A. Arnold, et al. 2020. "A new ecosystem for evidence synthesis" Nature Ecology \& Evolution 4(4): 498-501.

Odgers, Stephen. 2018. Uniform Evidence Law $13^{\text {th }}$ ed. Australia: Thompson Reuters.

Randall, Melanie. 2010 “Sexual Assault Law, Credibility, and Ideal Victims: Consent, Resistance, and Victim Blaming" Canadian Journal of Women and the Law 22(2) 397-434.

Rathus, Zoe. 2018. "The Research Says: Perceptions on the Use of Social Science Research in the Family Law System" Federal Law Review 46: 85-111.

Roberts, Andrew. 2019. “The Frailties of Human Memory the Accused's Right to Accurate Procedures" Criminal Law Review 11: 912-33.

Sheehy, Elizabeth, Julie Stubbs, and Julia Tolmie. 1992. "Defending Battered Women on Trial:

The Battered Woman Syndrome and its Limitations" Criminal Law Journal 16: 369-94.

Sheehy, Elizabeth, Julie Stubbs, and Julia Tolmie. 2014. "Securing Fair Outcomes for Battered Women Charged with Homicide: Analysing Defence Lawyering in $R v$ Falls" Melbourne University Law Review 38: 666-708.

Stark, Evan. 2007. Coercive Control: How Men Entrap Women in Personal Life Oxford: Oxford University Press. 
Stubbs, Julia and Julia Tolmie. 1995. "Race, Gender, and the Battered Woman Syndrome: An Australian Case Study" Canadian Journal of Women and the Law 8: 122-58.

Stubbs, Julia and Julia Tolmie. 1999. "Falling Short of the Challenge - A Comparative Assessment of the Australian Use of Expert Evidence on the Battered Woman Syndrome" Melbourne University Law Review 23: 709-48.

US DOJ (U.S. Department of Justice). 1996. The Validity and Use of Evidence Concerning Battering and Its Effects in Criminal Trials: Report Responding to Section 40507 of the Violence Against Women Act (Report No NCJ 160972).

Vazire, Simine, and Alex O. Holcombe, "Where Are The Self-Correcting Mechanisms In Science?” https://psyarxiv.com/kgqzt/.

Walker, Laurens and John Monahan. 1987. "Social Frameworks: A New Use of Social Science in Law”Virginia Law Review 73: 559-98.

Walker, Lenore E., Roberta K. Thyfault, and Angela Brown. 1982. "Symposium: Family Violence in America - Part II Beyond the Juror's Ken: Battered Women” Vermont Law Review 7(1) 1-14.

Webster, K., Diemer, K., Honey, N., Mannix, S., Mickle,, J., Morgan, J., Parkes A. et al. 2018. Australians' attitudes to violence against women and gender equality (Findings from the 2017 National Community Attitudes towards Violence against Women Survey, NCAS, Research Report).

Wootton, David. 2015. The Invention of Science A New History of the Scientific Revolution. UK: Allen Lane. 


\section{CASE LIST}

Clark v Ryan (1960) 103 CLR 486.

Dasreef Pty Ltd v Hawchar (2011) 243 CLR 588.

Daubert v Merrell Dow Pharmaceuticals Inc, 509 US 579 (1993), 113 S Ct 2786.

Ewert v Canada 2018 SCC 30.

Heilig v Cabiness [2011] FMCAfam 97.

Kalenik v Apostolidis [2009] VSC 208 [592].

Liyanage v WA (Western Australia) [2017] WASCA 112.

New Jersey v Kelly, 478 A 2d 364 (SC, 1984).

$R v$ Christie [1914] AC 545.

$R v D(D) 2000 \mathrm{SCC} 43$.

$R v$ Hamid [2006] NSWCCA 302.

$R v$ Jones [2015] QCA 161.

$R v$ Lalonde, 22 OR (3d) 275, 1995 CarswellOnt 9.

$R v$ Lavallee [1990] 1 SCR 852, 1990 CarswellMan 198.

$R v \operatorname{Li}$ [2016] SASC 4.

$R v M(M A)$ [1998] 1 SCR 123, 1998 CarswellOnt 419 (L'Heureux-Dubé J). 
$R v$ Mohan [1994] 2 SCR 9, 1994 CarswellOnt 66 [26]R v Osland (1998) 159 ALR 170 (Kirby

J).

$R v O^{\prime}$ Neil-Shaw [2009] NSWDC 48.

$R v$ Sica [2013] QCA 247.

$R v$ Silva [2015] NSWSC 148.

$R v S(J P) 50 \mathrm{WCB}(2 \mathrm{~d}) 161$.

$R v$ Reid 18 CR (6th) 350.

$R v$ Runjanjic \& Kontinnen (1991) 56 SASR 114 ('Runjanjic’).

$R v$ Tarrant [2018] NSWSC 774.

$R v$ Young 2008 BCCA 393.

State v Batangan, 799 P.2d 48 (1990).

State v Guilbert, 49 A.3d 705 (2012).

The Queen v Bonython (1984) 38 SASR 45.

WA (Western Australia) v Liyanage [2016] WASC 12.

WA (Western Australia) v Carlino [2014] WASC 404.

White Burgess Langille Inman v Abbott and Haliburton Co, 2015 SCC 23. 


\section{LEGISLATION}

NSW (New South Wales). 1995. Evidence Act, No 25.

US. Federal Rules of Evidence, 28 U.S.C. 